
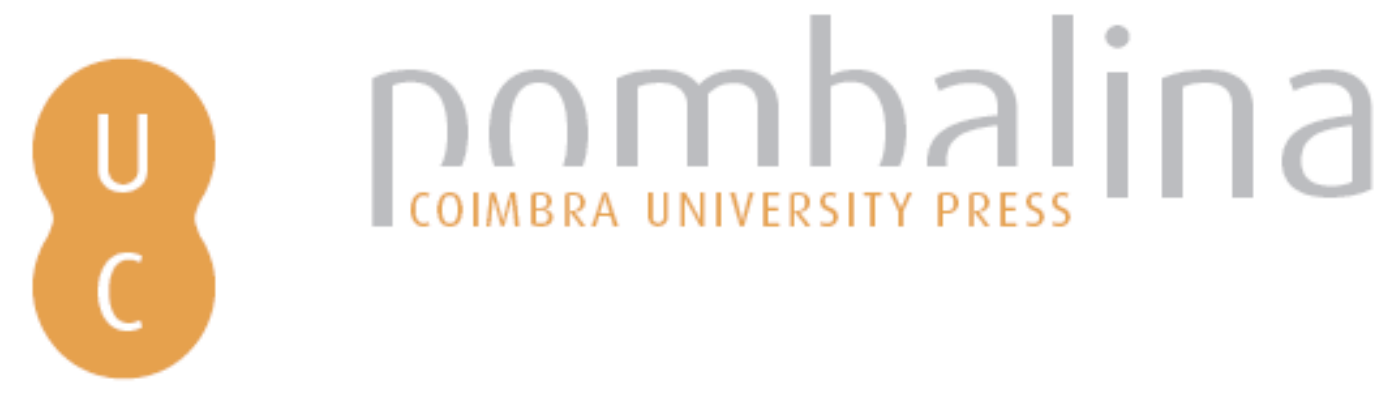

\title{
Rufianes, alcahuetes y terceras en los tratados de práctica jurídica y en los tribunales (La Real Chancillería de Valladolid, ss. XVII-XVIII)
}

Autor(es): $\quad$ Torremocha Hernández, Margarita

Publicado por: Imprensa da Universidade de Coimbra

URL

persistente: URI:http://hdl.handle.net/10316.2/37194

DOI: $\quad$ DOI:http://dx.doi.org/10.14195/978-989-26-1033-7_7

Accessed : $\quad$ 26-Apr-2023 14:59:34

A navegação consulta e descarregamento dos títulos inseridos nas Bibliotecas Digitais UC Digitalis, UC Pombalina e UC Impactum, pressupõem a aceitação plena e sem reservas dos Termos e Condições de Uso destas Bibliotecas Digitais, disponíveis em https://digitalis.uc.pt/pt-pt/termos.

Conforme exposto nos referidos Termos e Condições de Uso, o descarregamento de títulos de acesso restrito requer uma licença válida de autorização devendo o utilizador aceder ao(s) documento(s) a partir de um endereço de IP da instituição detentora da supramencionada licença.

Ao utilizador é apenas permitido o descarregamento para uso pessoal, pelo que o emprego do(s) título(s) descarregado(s) para outro fim, designadamente comercial, carece de autorização do respetivo autor ou editor da obra.

Na medida em que todas as obras da UC Digitalis se encontram protegidas pelo Código do Direito de Autor e Direitos Conexos e demais legislação aplicável, toda a cópia, parcial ou total, deste documento, nos casos em que é legalmente admitida, deverá conter ou fazer-se acompanhar por este aviso.

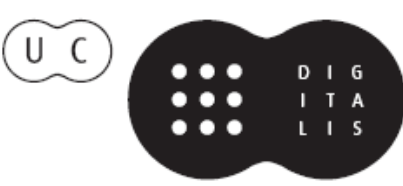


AS MULHERES PERANTE

OS TRIBUNAIS DO

ANTIGO REGIIME NA PENÍNSULA JBÉRICA

ISABEL M.R. MENDES DRUMOND BRAGA MARGARITA TORREMOCHA HERNÁNDEZ (COORDENAÇÃO)

IMPRENSA DA

UNIVERSIDADE

DE COIMBRA

COIMBRA

UNIVERSITY

PRESS 


\section{RUFIANES, ALCAHUETES Y TERCERAS EN LOS TRATADOS DE PRÁCTICA JURÍdICA Y EN LOS TRIBUNALES（LA REAL CHANCILLERÍA DE VALLA D O L I D , S S . XVII - X V I I I )}

Margarita Torremocha Hernández Universidad de Valladolid

\section{Una primera cuestión de terminología}

Tanto San Agustín como Santo Tomás, contemplaron la prostitución, como mal menor o, simplemente, como una utilidad pública ${ }^{1}$. No obstante en la consideración de este fenómeno hay que atender a una casuística muy variada, que atañe tanto a la forma en que ésta se desarrolla, como a los individuos implicados en ella, y su estado y condición.

Los tratos torpes, ilícitos y escandalosos que definen a la prostitución, están envueltos en distintas estimaciones; si se hacían voluntariamente o no, por ganancia o por vicio, si los implicados eran solteros o habían recibido el sacramento del matrimonio o los votos eclesiásticos, y un largo conjunto de posibilidades. En consecuencia, esta actividad se vio de distinta manera tanto por los teólogos, como por los juristas,

\footnotetext{
1 "Quita las sentinas en el mar o las cloacas en el palacio y llenarás de olor el palacio; quita las prostitutas en el mundo y lo llenarás de sodomía". Sergio Ortega Noriega, El Discurso Teológico de Santo Tomás de Aquino sobre el Matrimonio, La Familia y los Comportamientos Sexuales, México. UNAM, 1981, pp. 7-11. M. Torremocha Hernández, De la Mancebía a la Clausura. La casa de Recogidas de Magdalena de San Jerónimo y el convento de San Felipe de la Penitencia (Valladolid, siglos XVI-XIX), Valladolid, 2014, pp.15-24.
} 
y por la sociedad misma. Tuvo, por ejemplo, atenuantes, en función de si se hacía por dinero, y considerando que no peca el que paga, o en el caso de la relación consentida entre solteros. Así en el Manual de confesores de Azpilcueta este autor no es que considere que las prostitutas no pecan, sino simplemente se "olvida" de especificarlo, mientras que dedica mucho más espacio a hablar de los pecados que cometen los hombres por su causa ${ }^{2}$. Y por ello, los que más pecaban eran los casados.

De manera, que la visión de la prostitución guarda una irremisible conexión con el matrimonio y el adulterio. En este campo entraban en juego los cornudos, los maridos consentidores, las correderas, los terceros y rufianes, que contribuían a la oferta y la demanda de un mercado sexual que era constante en las villas y ciudades de Castilla. Por tanto, si las condiciones de este negocio eran variadas, también lo eran sus elementos ${ }^{3}$.

En la base de este comercio carnal está la mujer deshonesta, que el jurista Pradilla define así:

2 "Lo primero, que por este mandamiento se veda toda cópula carnal fuera de legítimo matrimonio; y por eso toda tal cópula es pecado mortal, aunque sea soltero con soltera, que se llama simple fornicación; tanto que decir lo contrario es herejía. Ni lo excusa desto la ignorancia, ni pensar que no es pecado conocer a mujeres públicas, porque es ignorancia de derecho natural y divino tan manifiesto que no excusa" (Compendio del manual de confesores, 1586, 16: 57v-58). Isabel Muguruza Roca, "Género y sexo en los confesionales de la contrarreforma. Los pecados de las mujeres en el Manual de confesores y penitentes de Martín de Azpilcueta”, Estudios Humanisticos. Filología, n. ${ }^{\circ}$ 33, 2011, pp. 195-218.

3 "En la primera mitad del siglo XVIII, el desarrollo del delito contra las personas no se relacionó exclusivamente con una progresión de la violencia sino también con la creciente preocupación de los tribunales por controlar el crimen sexual, particularmente la prostitución, bigamia, violación, adulterio y mantenimiento de cualquier tipo de relaciones consideradas ilícitas. Este problema se manifestaba con más intensidad en el mundo urbano que en el rural. Aunque los relatos sobre El Arenal sevillano y los burdeles madrileño o valenciano en fechas anteriores, así como las acciones de policía urbana, ya dan buena muestra de las complejas relaciones entre los gobiernos municipales y los burdeles, con la organización clandestina de la prostitución después del cierre legal de los burdeles en Castilla decretado en 1623 , así como con los fenómenos de atracción de jóvenes de ambos sexos ejercida por las ciudades y con las fragilidades de un caprichoso mercado laboral urbano que abría o cerraba oportunidades. Todos estos fueron factores que influyeron en la mayor progresión del delito sexual, aunque también en otras manifestaciones delictivas, ante los tribunales de justicia urbanos". Tomás Mantecón Movellán, "Los impactos de la criminalidad en sociedades del Antiguo Régimen: España en sus contextos europeos", Vinculos de Historia, n. ${ }^{\circ}$ 3, 2014, p. 67. 
"Para llamarse una muger deshonesta basta consentir que hombres, y particularmente clérigos y estudiantes continúen su casa, y la que de ordinario habla o escrive a hombres y consiente que le hallegen las manos, y a los pechos, y la besen, que todo suele ser junto, y a veces más escandaloso, que el carnal accesso tenido en secreto. Y ocurriendo juntamente con estos actos deshonestos, el trato y cópula carnal con los hombres, de modo que se venga a saber, mayor será el escándalo y deshonestidad. ...”4 .

La alcahueta, tal y como se deduce de la documentación procesal es, por lo general, una antigua prostituta que pasa de ganar con su cuerpo a ganar con el de otras mujeres. Pero, según el enunciado concreto de un auto de oficio son

"personas que se enplean en el oficio perjudicial y escandaloso de solicitar mugeres para que pequen en su casa, con los hombres que a ella combidan por su lucro e interés" 5 .

Así pues formulado, la alcahuetería no es un oficio/delito femenino, sino que lo ejercen tanto hombres como mujeres. El léxico varía pues ellos se conocen como alcahuetes, rufianes, consentidores, y ellas como terceras, corredoras, alcahuetas, entre otros muchos apelativos ${ }^{6}$. También varía el modus operandi, como hemos analizado en otros trabajos, el fin de la acción y el grado de implicación de los participantes ${ }^{7}$. En este sentido, los textos de práctica jurídica se adentran en los posibles arquetipos, y dan un mayor protagonismo al papel masculino de la alcahuetería frente a la actividad celestinesca puramente femenina que predomina en lo literario:

${ }^{4}$ Suma de las Leyes Penales por el Doctor Francisco de la Pradilla. Y adicionado por el Licenciado Francisco de la Barreda. Y ahora de nuevo añadido por el Licenciado Dn. Juan Calderón, Abogado de los Reales Consejos, 1639. Caso XXX. De las mugeres deshonestas, y que tienen acceso carnal entre si una con otra, pp. 48-49.

5 Valladolid, Archivo de la Real Chancillería de Valladolid (ARCV), Causas Secretas 10.12. 1764 .

${ }^{6}$ Juan Antonio Frago Gracia. Sobre el léxico de la prostitución en España durante el siglo $X V$, Zaragoza, Institución Fernando el Católico, 1979.

7 M. Torremocha Hernández, "De la Celestina al Alcahuete: del modelo literario a la realidad procesal", en prensa. 
"El delito de lenocinio se comete de diferentes modos. Lo primero quando hombre casado tiene por cierto y sabe que su muger le haze adulterio, y trata con otro y habita con ella, y quando tal hombre casado por su voluntad, y expreso consentimiento la entrega a otro hombre, por precio.

De otro modo se comete lenocinio y es quando un hombre o muger siendo terceros, a que llaman alcahuetes, procuran y solicitan que muger alguna sea conocida de hombre por carnal acesso...

De otro modo también se comete este delito, y es quando algún hombre tiene a muger en las casas que llaman públicas, y mancebías, para que le dé su torpe ganancia, los quales se llaman rufianes." ${ }^{8}$.

Por tanto, en cuanto a la tipología de delitos hemos de entender que existe la alcahuetería como concepto básico, al tiempo que variaciones numerosas en su formulación, y a su vez una clara diferencia entre prostitución y alcahuetería, que tienen una distinta consideración legal, aunque en la base común de ambos estén los tratos ilícitos y el escándalo.

La prostituta - no la cortesana - actúa por penuria. La tercera, que se beneficia del trabajo de ésta, interpreta su labor como una ayuda a las mozas que necesitan tener ingresos con premura; a tantas mujeres que llegan del campo a la ciudad, que buscan trabajo doméstico, que no encuentran o que solo las permite malvivir. Por ello, defienden su tarea como algo beneficioso para estas jóvenes, de las que se convierte en Madre.

Manuela Ortiz, que tenía casa abierta junto al Hospital de la ciudad de Burgos,

"Preguntada, confiese si en dicha su casa a tenido admittido y llevado mujeres y hombres para tratos ylizittos y ttorpes, dixo que unicamente y por caridad lo havia echo de algunas mozas desacomodadas ínterin encontraban donde serbir, sin haver admitido hombres en su casa para semejantes tratos...".

8 Suma de las Leyes Penales [...]. Cap. X. Del crimen y delito de lenocinio, y de los alcabuetes y encubridores. 
Atrevido parece incluir la palabra caridad, para definir su tarea. Pero coincide con otras correderas en que con ellas las mozas vivían bien, como decía Ana María Salcedo: “...y si bien es verdad que me e servido de algunas criadas mocas pero lo cierto es que a mi notizia no a venido que ayan vivido mal..."9. Otras afirmaban que aunque las dejaban ser visitadas por hombres, tardes y noches, lo hacían en la creencia de que - siendo las mozas solteras - se iban a casar después con ellas ${ }^{10}$.

No obstante, la tolerancia hacia los alcahuetes era menor en todos los ámbitos que hacia las putas. Las prostitutas aparecen en los procesos que se siguen contra las mujeres y hombres para los que han trabajado como valiosas testigos, capaces de aportar la información más apreciable y completa sobre las actividades de estos. En ningún caso se procede judicialmente contra ellas, ni tan siquiera en los discursos articulados por jueces, alguaciles, abogados, y cualquier miembro de este tribunal se hacen observaciones o juicios de valor contra ellas.

Curiosamente, si se procede en ocasiones contra algún cliente de estas casas de lenocinio, con apercibimientos procesales, como ocurre con un hombre llamado José García, mancebo de José de Lanziniego, vecino y cirujano de Burgos, por ocioso y malentretenido, al que se le apercibe para que en lo sucesivo no cometiera excesos, pena de 5 años en presidios de África ${ }^{11}$.

\section{Los procedimientos criminales en la teoría y en la práctica jurídica.}

Estos procedimientos criminales se inician por auto de oficio, una vez que los alcaldes del crimen o el gobernador de la sala tienen conocimiento de una situación delictiva, generalmente bajo la capa de escándalo, "sin que se les conozca otro destino que el acarrear vicios y daños al

\footnotetext{
9 Valladolid, ARCV. Causas Secretas 2.18. 1628.

10 Valladolid, ARCV., Pleitos criminales 1232-5, 1758.

11 Valladolid, ARCV., Pleitos criminales 1232-5, 1756.
} 
Atrevido parece incluir la palabra caridad, para definir su tarea. Pero coincide con otras correderas en que con ellas las mozas vivían bien, como decía Ana María Salcedo: “...y si bien es verdad que me e servido de algunas criadas mocas pero lo cierto es que a mi notizia no a venido que ayan vivido mal..."9. Otras afirmaban que aunque las dejaban ser visitadas por hombres, tardes y noches, lo hacían en la creencia de que - siendo las mozas solteras - se iban a casar después con ellas ${ }^{10}$.

No obstante, la tolerancia hacia los alcahuetes era menor en todos los ámbitos que hacia las putas. Las prostitutas aparecen en los procesos que se siguen contra las mujeres y hombres para los que han trabajado como valiosas testigos, capaces de aportar la información más apreciable y completa sobre las actividades de estos. En ningún caso se procede judicialmente contra ellas, ni tan siquiera en los discursos articulados por jueces, alguaciles, abogados, y cualquier miembro de este tribunal se hacen observaciones o juicios de valor contra ellas.

Curiosamente, si se procede en ocasiones contra algún cliente de estas casas de lenocinio, con apercibimientos procesales, como ocurre con un hombre llamado José García, mancebo de José de Lanziniego, vecino y cirujano de Burgos, por ocioso y malentretenido, al que se le apercibe para que en lo sucesivo no cometiera excesos, pena de 5 años en presidios de África ${ }^{11}$.

\section{Los procedimientos criminales en la teoría y en la práctica jurídica.}

Estos procedimientos criminales se inician por auto de oficio, una vez que los alcaldes del crimen o el gobernador de la sala tienen conocimiento de una situación delictiva, generalmente bajo la capa de escándalo, "sin que se les conozca otro destino que el acarrear vicios y daños al

\footnotetext{
9 Valladolid, ARCV. Causas Secretas 2.18. 1628.

10 Valladolid, ARCV., Pleitos criminales 1232-5, 1758.

11 Valladolid, ARCV., Pleitos criminales 1232-5, 1756.
} 
pueblo" 12 , "y para remedio de ttodo, su casttigo y evitar semejantes pecados públicos..."13.

No son causas, por lo común, que tengan una denuncia particular en forma, a pesar de que en muchas de las analizadas se vea que tras ellas está una comunidad vecinal molesta por el deterioro moral que les suponen sus actividades que, además, generan violencia. Algunos vecinos confiesan hasta haber cambiado de residencia como consecuencia de tener una casa de lenocinio en su entorno ${ }^{14}$. Pero incluso en esas causas, se procede por auto de oficio.

Los perjudicados, no acuden pues, por lo general, desde el principio a la justicia, aunque pronto se convierten en testigos. Son varios los pleitos en que los vecinos/testigos relatan uno tras otro que antes habían dado noticia de lo que ocurría al párroco del lugar. Que éste había reconvenido a los implicados, sin consecuencia alguna. La falta de éxito de la intervención de la Iglesia, a través de su miembro más cercano de la comunidad, es lo que da paso a la actuación en los tribunales. Es más, en alguna ocasión los párrocos rehusaron a entrometerse en casos de matrimonios consentidores, alegando de forma escrupulosa que no tenía pruebas suficiente para la amonestación que los vecinos le requerían, "que siendo casados hera cosa delicada; no viendo los vessar y abrazar a dicho privilexiado y mujer casada" 15 .

Sin embargo, la maquinaria judicial, una vez que ha sido informada, quiere saber y proceder. Otros miembros alertarán después - a lo largo de los procesos por alcahuetería - a la judicatura para que actuase contra estos delincuentes, como hizo el procurador fiscal interino al corregidor de Burgos:

12 Valladolid, ARCV., Pleitos criminales 1387-7, 1802.

13 Valladolid, ARCV., Pleitos criminales 1232-5, 1758.

14 "lo que la ha parezido mui mal y a toda la Bezindad por reputarla a esta y sus entradas y salidas cosa de alcahuetería”. Valladolid, ARCV., Causas Secretas, 12.3, 1767; “... es un continuo Serrallo e incomodidad para todo el vezindario y de cuias mugeres han resultado dañados muchos jobenes, por ser notorio estan absolutamente enfermas y perdidas...". "de todo lo qual esta escandalizada la vezindad e incomodada con el mal ejemplo y prostitucion de semejantes mugeres". Valladolid, ARCV. Pleitos criminales 1387-7, 1802.

15 Valladolid, ARCV., Causas Secretas 7-9. 1750. 
"Y porque siendo indispensable al noble ofizio de vm corregir i enmendar y aun precaver todo vizio maldad o delito en la República, o su distrito, desterrando de ella para que se conserve pura, las personas que las infizionan con imposición con digna de castigo; no tanto por infringir osadamente lo prevenido por las leyes Reales, por desfalcar los caudales y debilitar la naturaleza; quanto porque con las continuas subversiones de todas gentes y edades promueben a la Magestad divina a descargar su yra con tanta ofensa, zeloso de evitar con presteza tanto daño..."16.

Intervención en clara consonancia con lo que podemos leer en Política de Corregidores de Castillo de Bobadilla en el capítulo titulado "El Corregidor limpie de vicios la ciudad", en el que aunque no haya una observación explícita para el fenómeno de la prostitución o de la alcahuetería, se señala que este - como autoridad judicial - tiene la obligación de limpiar la República de hombres viciosos ${ }^{17}$.

En los encabezamientos de los procesos, iniciados casi en su totalidad a través de autos de oficio, se puede aventurar las razones que los promueven: "sobre admitir a su casa mugeres deshonestas"; o en otro auto de oficio por el que se iniciaba una causa contra unos terceros, el alcalde del crimen anotaba: "Dixo que en la calle y sittio de esta ciudad que se expresara en este testimonio secreto y separado, biben dos personas que se enplean en el oficio perjudicial y escandaloso de solicitar mugeres para que pequen en su casa, con los hombres que a ella combidan por su lucro e interés", incidiendo por tanto en la mercantilización del cuerpo de las mujeres, más que en lo escandaloso. En la misma línea se inicia otra investigación contra una mujer "llamada Teresa Guezmes, reputada por viuda, que admite en su casa a diferentes criadas de servicio, a quienes solicita para tratos ilícitos, con todo género de personas...", en la que se destaca tan solo la utilización que hace de las mozas. Otras solo calificadas "sobre el abominable delito de lenocinio", como también la que,

16 Valladolid, ARCV., Pleitos criminales 1232-5, 1758.

17 Castillo de Bovadilla, Política de Corregidores y señores de vasallos, Madrid, 1759 Libro II, cap. XIII, 38,39, pp. 454. 
entrado el siglo XIX, se inicia por unos "autos formados del real oficio contra Simón Labajos, y Josefa Gallardo, su conjunta, de esta vecindad sobre cabronismo, prostitucion y alagueteria", pues se perseguía una actividad concreta, sin citar ni el escándalo ni el servicio que se dejan hacer por las mujeres.

A partir del inicio de la información, solicitada por auto de oficio por los alcaldes del crimen o su gobernador, podemos conocer cómo se debe proceder en los tribunales siguiendo las indicaciones del abogado Miguel Cayetano Sanz, que a través de su obra, publicada en 1774, nos acerca al Modo y forma de instruir y substanciar las causas criminales de alcahuetería y lenocinio. Establece cinco puntos en los que estudia cómo ha de ser su sustanciación. El primero es una clasificación ${ }^{18}$ :

"Aunque la Ley Partida pone cinco géneros de Alcahuetes y Reynaldo los reduce a quatro, pueden todos entenderse en tres casos: el primero, quando el marido es alcahuete de la muger, del que ya tenemos hablado: el segundo, quando el Padre o Madre lo son de las hijas, criadas, o parientas: y el tercero, quando alguno o alguna solicita y busca mujeres, y hombres para que vayan a su casa, y allí tengan actos carnales"19.

De tal manera que se aconseja, o se deduce, que el juez atenderá a la ligazón del delincuente con las mujeres que utiliza para su enriquecimiento: esposa, mujeres de la familia, otras que no son familia. José Marcos Gutiérrez, dirá más adelante, que esta relación debería marcar

18 Otra clasificación posterior: "La primera clase es la de la que sirven de corredores o medianeros para que las mugeres que están en sus propias habitaciones delincan con aquellos de quienes en premio de su vileza reciban algún interés: la segunda es de los que tienen en su morada mugeres infames que hacen un vil comercio de sus cuerpos, y perciben lo que ellas lucran por este medio: la tercera es de aquellos viles maridos que alcahuetean a sus mugeres; y la cuarta es la de los que por algún lucro consienten que en su casa cometan torpezas mugeres casadas u otras decentes, sin ser medianeros entre ellas y sus cómplices". José Marcos Gutiérrez, Práctica criminal de España, Madrid, Imprenta de Dn. Fermín Villalpando, 1819, p. 192.

19 Miguel Cayetano Sanz, Modo y forma de instruir y substanciar las causas criminales: obra utilísima para juezes, asesores, abogados, escribanos, y demás curiales de qualesquiera Tribunales del Reyno, así eclesiásticos como seculares, Valladolid, Tomás de Santander, (1774). Caso XXVII. 
diferencias en el delito y por tanto en la pena, algo que no se hacía, pues entre los rufianes "unos son mucho más detestables que otros, los padres y maridos que prostituyen a sus hijas y mugeres, mucho más culpados que los que prostituyen mugeres con quienes no tienen ninguna relación natural ni social" 20.

En segundo lugar atiende al delito y su probanza:

"Y para la justificación del cuerpo de este delito, es necesario probar: lo primero, que el hombre, o muger, que hace esto, lo executa por interés, porque este es la causa formal del Lenocinio: lo segundo, que en fuerza de las solicitudes, o sin ellas, haya avido realmente actos carnales: lo tercero, que por dos veces a lo menos haya sucedido lo referido, como todo lo advirtieron Reynaldo, y Azevedo y en estas causas son testigos idóneos, asi los hombres, como las mujeres, que allí concurrieron, y que executaron los actos torpes, como dixo el Señor Matheu"21.

Además - en tercer lugar - en estas acusaciones de escándalo, a la hora de enjuiciar, se debe valorar la publicidad de los actos, y en consecuencia se ha de dirigir a los testigos para que aporten información en este sentido. Los testimonios han de ser detallados, aportando sobre las "entradas y salidas" en los domicilios, la búsqueda o no de discreción y por tanto la capacidad de escandalizar. En este discurso se aprecia que son objeto de análisis las actuaciones dirigidas a ocultar algo prohibido, tipificado como delito, y no las que buscan intimidad para los actos carnales.

“También se han de examinar los Vecinos y demás, que supiesen del caso, para que digan quienes entraban, y salían, y demás que huviesen visto u oído".

${ }^{20}$ José Marcos Gutiérrez, Práctica criminal de España [...], pp. 192-193.

${ }^{21}$ La obra mencionada es el Lorenzo Matheu Sanz, Tractatus de re criminali sive Controversiarum usu frequentium in causis criminalibus, cum earum decisionibus, tam in aula suprema hispana criminum, quam in summo senatu novio orbis, 1676. Francisco Aguilar Piñal, "Alonso María de Acevedo. Un sevillano ilustre del siglo XVIII", Archivo Hispalense, LXXIV, $\mathrm{n}^{\circ} 225,1991$, pp. 39-49. 
Los vecinos no tenían problemas en detallar la vida de los investigados pues en aquella sociedad donde el concepto de intimidad no estaba en uso, se fijaban en todo; y más en todo lo que provocaba escándalo. En el caso de la viuda que utilizaba su casa para las citas y buscaba hombres y mujeres para concertar los encuentros decían:

“...sin embargo ha visto la continuación de enttradas y residenzias en dicha casa de mozas como de serbizio y tiene por cierto según lo que se obserbaba que a persuasiones de la Theresa dichas mozas estavan en la casa para con ttodo jenero de personas tener trattos ilícitos. $\mathrm{Y}$ en esto se remite a la Boz jeneral del senttido y juizio que ha hecho ttoda la bezindad pues esta por publico reputaban por alcabuetta a la insinuada Theresa...".

El testimonio de Manuela Bachiller, casada, vecina del barrio de San Martín, de 47 años de edad, afirmaba que la conocía, que tenía por viuda, que a su casa entraban y salían a todas horas hombres y mujeres "lo que la ha parezido mui mal y a toda la Bezindad por reputarla a esta y sus entradas y salidas cosa de alcahuetería". Es más, lo aseguraba "porque muchos hombres equibocados han solido preguntar así en la casa de la deponente como en la de los demas Bezinos donde vive por aquí una viuditta que se llama Theresa y tiene unas hijas". Otra vecina la dijo que admitia mozas de servicio, "y a estas las solizitava para trattos ilicitos" 22 .

Finalmente, - en cuarto y quinto lugar - Cayetano Sanz señala que en la práctica jurídica de la Edad Moderna había que respetar a las personas de calidad que pudieran estar implicadas. En esta sociedad jerarquizada, los procesos que se siguen por alcahuetería, en los que se ven implicados hombres o mujeres de posición o privilegiados, guardan un distinto procedimiento en los tribunales.

"En los Autos que sobre este delito se formasen se han de expresar los nombres, y apellidos del Alcahuete o Alcauheta, y los de las mujeres que ocurrieron, siendo estas comunes, publicas y escandalosas, y

22 Valladolid, ARCV, Causas Secretas, 12.3, 1767. 
lo mismo se ha de executar, respecto de los hombres de igual clase, y esfera: pero si los concurrentes fuesen personas Eclesiasticas, Religiosas, o de buenas circunstancias, entonces no se han de expresar en los Autos los nombres, que se han de poner en testimonio separado" 23 .

La ocultación en los procesos de personas de consideración social es un fenómeno común en las actuaciones de los jueces.

"Y tal vez por proceso secreto y sumario podrán mandar salir de la ciudad a alguna muger soltera, y aun casada de buena estofa, pero de incorregible, y escandalosa vida, haviendola primero amonestado secretamente: lo qual se pueda hacer aun sin citación...y aunque no se expressa la causa; antes pareciendo necesario para más disimulación se pueda expresar y fingir, que es por otra ocasión y causa, que aunque sea culpable no infame..."

\section{Toda precaución podía ser poca en estos casos}

"Suele, en estas ocasiones de procesos sumarios y secretos, en que se trata de honra de mujeres, o de personas principales, usarse de cautela, en escribir el mismo Corregidor o Teniente por su mano a los mismos testigos, que deponen en el caso, sin intervención del Escribano, y guardarse el tal proceso en su escritorio,... todavía en algunos casos leves y breves, y en que de la publicidad pueden resultar escándalo..."24 .

También en el siglo XVIII, Alonso de Villadiego en su Instrucción Política y práctica judicial..., escribía en el mismo sentido para instrucción de los jueces:

"Y si se tratase algún negocio de amores de personas principales, ò doncellas honrradas, ò Religiosos, ò de muger casada, tratelo con secreto, y en apartado, y lo mismo cualquier otro negocio que requiera secreto".

\footnotetext{
23 Miguel Cayetano Sanz, Modo y forma de instruir [...].

24 Castillo de Bovadilla, Politica de Corregidores [...], Libro II, cap. XIII, 48, pp. 457-458.
} 
En efecto, al estudiar los procesos seguidos por alcahuetería es frecuente que todos los trámites procesales se sigan sin mencionar a ninguna de las partes, asignando a cada individuo un número o letra que se corresponde con un nombre, cuya equivalencia es posible que se encuentre bien en hoja suelta inserta con el proceso, o cosida con toda la documentación de la causa, en la parte final. Después, cada vez que el juez inicia pesquisas o interrogatorios se advierte a los implicados que han de contestar con la cautela de omitir los nombres y por tanto evitar la identificación directa. El criterio para establecer el secreto lo ponía el juez, y se observa con frecuencia, que sin ser personas de calidad, pero sí mujeres casadas lo implanta, no teniendo la misma prevención si son solteras. Esto supone un respeto y protección al matrimonio y a los maridos, resultando más desprotegidas las solteras, también en lo legal.

Entre estas personas de calidad, incluso privilegiadas, están los clérigos con queridas en los que tanto la ley como los tratadistas se detienen de forma extensa. Estos cuando se ven inmersos en un procedimiento por tratos ilícitos o alcahuetería consiguen que sean silenciados sus nombres, aunque otras simplemente se notifican los hechos a la jurisdicción eclesiástica para que proceda contra ellos. La tendencia a amancebamientos más o menos estables de los clérigos fue una realidad que a nadie se le ocultaba $^{25}$. Quizás por ello el abogado/relator Miguel Cayetano Sanz, incluye en sus instrucciones lo que se debe hacer:

"Si alguno de los concurrentes fuese Clerigo, o Frayle se sacará testimonio de la culpa, que contra él resulta y se remitirá a su Juez; y lo mismo se hará en otro qualquiera caso, en el que, Clérigo o Frayle tratasen ilícitamente con aquella muger contra quien se procediese”. [...].

25 “...porque el sacerdote amancebado o fornicario, aun oculto, que sin propósito de nunca tornar a ello se confiesa y celebra, tres pecados mortales comete: el primero no echar de sí la manceba o fornicaria, que es muy grande y propincua ocasión de pecar; el segundo, recebir la absolución en pecado mortal; el tercero osar celebrar y recebir tan santo sacramento en tan sucio estado. [...] que si muriesen en tal pecado público no se habían de enterrar en sagrado. Lo cual se debe notar para los que mueren teniéndoles la candela las mancebas desvergonzadas". Martín Azpilcueta, Manual de confesores y penitentes, Coimbra, 1553. 
“...pero si los concurrentes fuesen personas Eclesiasticas, Religiosas, o de buenas circunstancias, entonces no se han de expresar en los Autos los nombres, que se han de poner en testimonio separado".

Otros autores como el P. fray Juan Enriquez en sus Questiones practicas de casos morales..., se adentran incluso en cuestiones más concretas como en la obligación que tiene la mujer que ha tenido tratos con un religioso y este le ha hecho regalos de valor de restituirlos al convento en el que este reside 26 .

\section{Penas y sentencias a alcahuetes según las Leyes del Reyno.}

Las sentencias por alcahuetería en la legislación castellana responden a la atención que las leyes de Castilla habían prestado a este delito, pero a lo largo de la Edad Moderna la costumbre fue imponiendo variaciones, que a finales del siglo XVIII se observaron y analizaron por distintos juristas.

Ya el Fuero Real atendió al delito de la alcahuetería, considerándolo grave, y lo castigaba con severas penas, tanto para el rufián como para las mujeres públicas, fueran libres o siervas, aunque más duras con és$\operatorname{tas}^{27}$. En las Partidas tras organizar las modalidades de alcahuetes ${ }^{28}$ se establecía condena al marido que consentía el adulterio o al que cometía lenocinio con su mujer con la misma pena señalada a los adúlteros. El problema radicaba en que a éstos el derecho real castellano no les imponía pena, sino que los entregaba al poder del marido, lo cual no podía aplicarse al marido alcahuete. En el siglo XVII, era usual que el marido

${ }^{26}$ Juan Enriquez, Farnese, Questiones practicas de casos [...], Cuestión primera, sección VIII, El sexto mandamiento de no fornicar, pp.41 y ss. Cuestión 16 A que está obligada la muger que ha tenido trato deshonesto con un religioso, p. 45.

27 "Toda muger que por alcahueta en mandado de algún home o de alguna muger casada o desposada, si pudiere ser sabido por prueba, o por señales manifiestas, el alcahueta y el que la embió sean presos e metidos en poder del marido o del esposo para facer de ellos lo que quisiere, sin muerto o sin lisión de su cuerpo, si el Pleyto no fuere ayuntado: e si fuere ayuntado muera la alcahueta por ello....".

${ }^{28}$ Partidas, VII, 22, 1. 
se vengara sin esperar a que fueran puestos en su poder los adúlteros en virtud de sentencia judicial, y el siglo XVIII fue abriendo paso a la intervención judicial con la pena de prisión para el adúltero ${ }^{29}$.

No obstante, desde las Cortes de Ocaña de 1469 se mandó que las prostitutas "mugeres públicas, que se dan por dinero, no tengan rufianes". Para ellas la pena era de cien azotes "por cada vez que fuere hallado que lo tiene publica o secretamente» y pérdida de toda su ropa; mientras que a dichos rufianes eran condenados a cien azotes por la primera vez, destierro perpetuo de la Corte y el lugar donde fueren hallados, la segunda, y en la tercera ocasión "mueran por ello enforcados"30. Pero, poco después, por la Pragmática 1552 se agravó la pena inicial de azotes prevista por "que le traigan a la vergüenza, y sirva en las nuestras galeras diez años"; en caso de reincidencia, cien azotes y galeras perpetuas, con la consabida pérdida de la ropa en ambas ocasiones; y se interpreta, que con muerte la tercera vez 31 .

Por otra Pragmática de 1566 se igualaba en estas penas aplicadas a los rufianes y a "los maridos que por precio consintieren que sus mugeres sean malas de su cuerpo, o de otra qualquier manera las induxeren o traxeren a ello", es decir, a los llamados consentidores, aunando por tanto alcahuete de la mujer con adulterio ${ }^{32}$. La identificación hacía que la pena fuera la misma, pero si tenemos en cuenta que para la adúltera la pena podía estar en la venganza privada del marido, aquí no se podían asumir las mismas consideraciones y la pena no quedaba pues definida.

Además, y con carácter general se prohibieron las mancebías públicas en $1623^{33}$, con una medida que no acababa con la prostitución ni la alcahuetería, sino que la dejaba un campo libre de acción, al margen de la organización que existió en la etapa medieval en torno a este oficio. De hecho, hasta esa fecha, existían además de tales leyes del Reino,

29 Tomás y Valiente, Francisco, El derecho penal de la monarquía absoluta (siglos XVI, XVII y XVIII), Madrid, 1969, pp. 75 - 76, 386 y 395. Partidas, VII, 17, 7

30 Nueva Recopilación, 8, 11, 4; Novísima Recopilación, 12, 27, 1.

31 Nueva Recopilación, 8, 11, 5; Novísima Recopilación, 12 27, 2.

32Recopilación, 8, 20, 9; Novísima Recopilación, 12 27, 3.

33 Novísima Recopilación, 12, 26, 7. 
disposiciones particulares vinculadas a las mancebías ${ }^{34}$. Y, no obstante, tras su desaparición fueron numerosos los fueros y ordenanzas de las villas y ciudades que reglamentaron la presencia de las alcahuetas. Caso de Valladolid, ligado al gremio de hospederos.

"Otro sí mandamos y ordenamos que ningún mesonero, ni mesonera, ni persona que en su casa acogiere, tenga con achaque de su servicio moza, ni criada, que gane pública, ni secretamente, porque dello vendría mucho daño a la República y a los huéspedes y caminantes, so pena que por la primera vez pague el huésped o huespeda que lo consintiere en su casa quinientos maravedís, por la segunda, mil maravedís, y por la tercera cien azotes, como alcahuete o alcahueta,..."35.

A mediados del siglo XVII, Pradilla, en Suma de las Leyes Penales, obra en la que, también se establecía una clasificación en el delito del lenocinio, nos aporta las penas correspondientes que se aplicaban en los tribunales.

Al marido consentidor o alcahuete de su mujer, "la pena de tal delito era la muerte. Pero ya por la general costumbre en España y otras la pena es que tales hombres viles, e infames, sean açotados públicamente por sus mismas mugeres con una rastrada de ajos, y llevan mitras o coroças en la cabeça con muchos cuernos al cuello, y otros son untados con miel y emplumados”.

Cuando se habla de alcahuetería la cometa hombre o mujer, "antes a estos semejantes conciliadores de voluntades, se les daba, y ponía pena de muerte, siendo las mugeres solicitadas doncellas, casadas o viudas honestas. Pero ya por dicha general costumbre los empluman y llevando

${ }^{34}$ Así, en un nivel espacial más concreto, en 1572, el arzobispo de Granada, decretó que las alcahuetas primerizas debían ser castigadas a hacer penitencia en la puerta de la Iglesia, coronadas con una mitra: y si reincidían debían recibir, en público, 200 latigazos y un exilio mínimo de 2 años. Beatriz Moncó Rebollo, "De dueña a esclava: breve esbozo de una tipología femenina", Anales de la Fundación Joaquín Costa, 1989, pp. 51-64.

35 Ordenanzas con que se rige y gobierna la república de la muy noble y leal ciudad de Valladolid, en las cuales se declaran todos los artículos tocantes al pro-común de ella. Valladolid, Imprenta de Roldán, 1818. En Eugenio Larruga, Memorias políticas y económicas sobre los frutos, comercio, fábricas y minas de España: con inclusión de los reales decretos, ordenes, cédulas..., Valladolid, Madrid, Don Antonio de Espinosa, 1792-1793. Tomo XXIII?, p. 45. 
coroças en las cabeças, son públicamente avergonçados, como refieren los doctores arriba referidos".

Los rufianes que tienen lupanares o casas públicas. "Y aunque como es dicho antes tenían pena de muerte, aora que demás de ser infames por Derecho nuevo del Reyno; los tales rufianes tienen pena, que por la primera vez sean açotados, por la segunda desterrados perpetuamente, por la tercera ahorcados. Y las tales mugeres que con ellos fueren, tienen pena de duçientos açotes, mas la ley acrecienta la pena y mandan que los rufianes, aunque no tengan sino diez y siete años, por la primera vez sean sacados a la vergüença, y condenados al servicio de galeras durante diez años”36.

La pena capital se aplicaba, si por la casuística los delitos se agravaban, actuando con mayor severidad la justicia: “...El hombre que tiene accesso con alguna muger, o la corrompe con algún palo, o otro instrumento material, tiene la dicha pena de muerte..." 37.

A través de la exposición de este jurista contemporáneo, es posible observar dos fenómenos. En primer lugar la tendencia, a la disminución de las penas, evitando la pena capital. En segundo que las penas principales para estos delitos fueron en cualquier caso penas infamantes y corporales.

En la mitad del siglo XVIII, el jurista Berni Catalá mantenía la opinión que en el tratamiento de las penas se estaba viviendo un proceso de mitigación por parte de los tribunales. Esta tendencia general, afectaba y en concreto beneficiaba también a los alcahuetes, quienes vieron reducir -según Pradilla ya en el Seiscientos - la pena de muerte en que estaba sancionada su conducta por otras corporales.

También lo mantenía a comienzos del siglo siguiente J. Marcos Gutiérrez:

"Mas no obstante pareciendo (y con razón) demasiado rigoroso para los alcahuetes el suplicio capital, se ha conmutado por principio general de los tribunales, con la pena de azotes, con la de salir emplumados, para cuyo efecto se les baña o unta el medio cuerpo con miel,

36 Suma de las Leyes Penales [...]. Capítulo X. Del crimen y delito de lenocinio, y de los alcabuetes y encubridores.

37 Ibid. Caso XXX. De las mugeres deshonestas, y que tienen acceso carnal entre si una con otra, pp. 48-49. 
u otro ingrediente pegajoso, y se echan encima las plumas: o con la de sacarlos con coroza en que se ven pintadas varias pinturas alusivas a sus delitos; y después se les destina a los hombres a presidio, y a las mugeres a la galera. Tocante a los maridos consentidores, quienes han de ser emplumados, se les suele poner pendiente del cuello una sarta de astas de carnero, y luego se les envía a galeras" 38 .

Pero, para poder respaldar tal afirmación, son necesarios trabajos y estudios cuantitativos más sistemáticos sobre delitos y sentencias. Los realizados por Ortego Gil, en la Real Audiencia de Galicia insisten en esta atenuación punitiva ante la práctica de su Sala del Crimen de finales de esta centuria, cuando, por ejemplo, castigó a una alcahueta, ante la falta de una casa galera en Coruña, con ocho años de destierro veinte leguas fuera de esta y Sitios Reales, además de apercibirla.

J. Marcos Gutiérrez, a comienzos del XIX, proponía como penas apropiadas para estos delitos de deshonestidad, las penas de infamia y privación de ciertos derechos, honores y facultades propias de las mujeres. Estas penas, con origen según su teoría en el Antiguo Egipto, debían cumplir una serie de requisitos: para establecerlas debe el legislador consultar la opinión pública, no se han de prescribir a quienes ningún aprecio hacen al honor, conviene formar entre ellas varias clases o grados, para que ridiculicen más o menos, y no deben trascender a los que tengan alguna conexión o parentesco 39 .

Entre ellas, la que se aplicó con más frecuencia y se recoge en los textos legales fueron las de azotes. Esta pena corporal estaba reservada para personas del estado llano, y no se aplicaba a hidalgos. Suponía una exposición a la vergüenza ante la comunidad, que tenía a su favor no dejar en el cuerpo vestigios permanentes como marcar con hierro o cortar las orejas ${ }^{40}$.

38 José Marcos Gutiérrez, Práctica criminal de España [...], pp. 193-194.

39 Ibid. pp. 167-168.

40 Pedro Ortego Gil, "Algunas consideraciones sobre la pena de azotes durante los siglos XVI-XVIII", Hispania, 22,3, n 212, 2002, pp.849 
La doctrina coincide en que, desde el medievo y aun en el siglo XVI, el marido alcahuete (que consentía el adulterio) era castigado a ser públicamente azotado por la propia mujer, y como señaló Tomás y Valiente ello había de ser considerado en sí mismo como una pena de vergüenza pública. También en Portugal se azotaba a los alcahuetes y se les expulsaba, siendo condenados a pena de muerte en caso de reincidencia ${ }^{41}$. Y si nos fijamos en otros reinos podemos tomar como ejemplo el caso mallorquín que refiere Antonio Planas Rosselló, de una condena de 1455 "a un marido a correr la villa con azotes, por consentir el adulterio de su mujer" 42 .

La pena de azotes era de las más temidas en Castilla y se utilizaba frecuentemente por su carácter intimidatorio. En el siglo XVIII distintos juristas reflexionaron sobre esta pena y su aplicación social. Lorenzo Matheu y Sanz señalaba en su Tractatus de re criminali (Madrid, 1776), que era más temida que la pena capital y, en ocasiones, permitía evitar esta última por su carácter intimidatorio, al ser utilizada con delitos leves, evitando la comisión de otros mayores. Sin embargo, como no se aplicaba en las jurisdicciones privilegiadas la pena había caído en cierto desuso.

Manuel de Lardizábal mostraba en su libro la representación que la Real Audiencia de Mallorca hizo a Felipe V, en la que afirmaba la eficacia de la pena de azotes por infundir "más horror" que la de galeras o presidio $^{43}$, pero la consideraba dura en exceso, sobre todo si la infamia de haberla recibido era mayor que la que marcaba el delito. Solo debería aplicarse para delitos que sean en sí

"viles y denigrativos, pues de lo contrario la pena misma causará un daño mayor, acaso, que el que causó el delito, que es hacer perder la

${ }^{41}$ Jesús Lalinde Abadía, Las culturas represivas de la humanidad, Zaragoza, 1993, t. II, p. 826

42 "Los delitos contra el matrimonio y la moral sexual en el Derecho histórico de Mallorca”, Bolletí de la Societat Arqueològica Lul.liana: Revista d'estudis històrics, 56, 2000, pp. 45-64;" Las penas en el derecho histórico de Mallorca”, Bolletí de la Societat Arqueològica Lul.liana: Revista d'estudis històrics, 55, 1999, págs. 85-118.

43 Manuel de Lardizábal y Uribe, Discurso sobre las penas, contrabido a las leyes criminales de España, para facilitar su reforma, Joaquín Ibarra, Madrid, 1782. 
vergüenza al que la sufre y ponerle por consiguiente en estado de que se haga peor en vez de enmendarse. Pero impuesta con prudencia y discreción podrá ser útil y contener con su temor".

Este mismo autor precisaba aún más en lo relacionado con los azotes dados a mujeres:

"quando se sacan las mugeres a vergüenza, de llevarlas desnudas de medio cuerpo arriba con los pechos descubiertos, lo que ciertamente ofende la modestia, y he visto causar este efecto aun en las gentes del bajo pueblo. En algunas partes van cubiertas por delante, dexándoles solamente descubiertas las espaldas, lo que es más conforme a la decencia, y por otra parte no disminuye en nada la pena de vergüenza".

Marcos Gutiérrez, por su parte, recomendaba utilizarlos con menos frecuencia, y reconocía sin embargo su utilidad, proponiendo que se implantase en las prisiones, aplicadas como tratamiento correccional y no como medio de tortura.

En definitiva, en la segunda mitad del siglo XVIII los juristas empezaban a rechazar o al menos a poner precauciones sobre penas infamantes de origen antiguo o medieval, a pesar de estar contenidas en leyes vigentes. De hecho, la Novísima Recopilación seguía incluyendo durísimas disposiciones contra gitanos y vagos a los que se castigaba con azotes, mutilaciones, galeras e incluso la muerte.

En cualquier caso, la pena de azotes no fue solemnemente abolida hasta las Cortes de Cádiz, en virtud de un Decreto de 17 de agosto de 1813 (en las escuelas y colegios) y de 8 de septiembre de 1813 (en los Tribunales de la monarquía y parroquias de Indias).

El destierro fue también pena común para estos delincuentes, así como para las prostitutas ${ }^{44}$. Mayoritariamente los juristas no la consi-

44 Margarita Torremocha Hernández, "La prostitución a través de la justicia penal: definición y control de la moral sexual en la Edad Moderna”, XIII Reunión Científica de la Fundación Española de Historia Moderna, Sevilla, 2014. 
deran pena corporal, pero normalmente, acompañaba a los azotes y de vergüenza pública, que si lo eran ${ }^{45}$. El destierro podía ser según José Marcos Gutiérrez de todo el Estado, al que se llama "extrañamiento del reino", o de un pueblo determinado; el segundo debía imponerse solo por delitos hijos del odio o el amor, como solía ser para estos casos ${ }^{46}$.

Esta pena originó debate. Castillo de Bovadilla, en su Política de Corregidores hace una valoración de la querella:

"Son algunos de opinión, que la pena más a propósito para la enmienda del rico es la de destierro, y al pobre la del dinero; porque el pobre sentirá más la hacienda que le falta, y el rico el sosiego que desea. A otros les parece lo contrario; que el pobre sea desterrado, y en dinero el rico condenado, y en que no salga de la Ciudad por algún tiempo, porque la privación de libertad le es de mayor temor, y castigo: ...Y por ventura los señores Inquisidores con esta consideración no destierra a los penitenciados, antes los mandan guardar con gran cuidado, y que sean entretenidos, en que no inficionen a otros, y se vea cómo viven públicamente..." 47 .

El verdadero problema de esta pena estaba en garantizar su ejecución y cumplimiento. El tribunal de Chancillería de Valladolid procura que los condenados sean llevados a la distancia impuesta de la ciudad a través de una serie de justicias de las localidades cercanas, hasta el lugar señalado por el juez, que a veces era el de su naturaleza. Pasaban de unas manos a otras, y cuando llegaban a su destino, las familias o la justicia del lugar quedaba encomendada de vigilar al condenado a destierro.

Magdalena de San Jerónimo, entre los provechos de crear una casa galera en las ciudades cita la posibilidad de poder controlar realmente a las alcahuetas y prostitutas, algo que no ocurría con las penas infamantes o de destierro:

\footnotetext{
45 Tomás y Valiente, Francisco, El derecho penal [...], pp. 261 y 392.

46 José Marcos Gutiérrez, Práctica criminal de España [...], p. 160.

47 Castillo de Bovadilla, Política de Corregidores [...], Libro II, cap. XIII, 57, p.460.
} 
"Iten, tendrá más eficacia y fuerza la ejecución de la Justicia, y alcanzarse ha mejor el fin que con los castigos públicos se pretende, que es la enmienda del delincuente y el escarmiento de los demás. Lo cual antes solía muchas veces ser al revés, y causa de mayores males azotar alguna de estas mozas y sacarlas a la vergüenza por las calles públicas y desterrarlas de la ciudad; y apenas se había hecho esto y saliéndose por una puerta cuando se entraba por otra; y así quedaba con mayor libertad y menos vergüenza.

Otras se van a otros lugares, a donde comienzas a hacer nuevos daños; y mujeres ha habido que desterradas de un lugar han corrido todos los buenos de España, con harto detrimento así de las almas como de los cuerpos, a los cuales han pegado enfermedades contagiosas y a veces incurables; todo lo cual cesa, recogiéndolas en esta Galera el tiempo que su delito mereciese. Y esto se ve aún más claro en las alcahuetas y hechiceras, a las cuales con sólo encorozarlas y pasearlas y desterrallas se contentaba la justicia. Pero como la llaga no se curaba de raíz si no estaba sobre sana, reverdecía luego, en yéndose a otras partes donde no eran conocidas; y allí ponían de nuevo sus tiendas y escuelas, con gran daño de toda la República: pero echándolas en la Galera y deteniéndolas uno o dos años, o lo que la Justicia juzgare merece su delito, ellas quedarán bien castigadas y atajados estos daños”.

La docena de mujeres públicas que fueron apresadas en la misma casa del barrio de la Vitoria de Valladolid, por sentencia se las confina a los pueblos de su respectiva naturaleza o domicilio y se encarga a los pueblos de su justicia celen y velen sobre sus conductas.

"Y no siendo arreglada la oviese conforme a derecho. Que sus justicias velen para que se apliquen a trabajo y oficio honesto, para mantenerse, con encargo especial a sus padres, parientes mas cercanos o curadores para que así lo cumplan bajo de toda responsabilidad, sin permitirlas salgan sin su expresa licencia del término y jurisdicción, no habiendo un motivo urgente. Serían conducidas por tránsito de justicia en justicia a sus citados pueblos" 48 .

48 Valladolid, ARCV, Pleitos criminales, 1300-11,1807. 
Pero a pesar de este complejo sistema de ejecución, en muchos procesos, transcurrido escaso tiempo se notifica al tribunal que sentenció que el condenado ya no se encontraba en el lugar. El quebrantamiento de esta condena fue especialmente notorio:

"La pena de destierro precisso y voluntario se pone a arbitrio del juez, en muchos casos y delitos dichos, y el desterrado deve cumplir el tiempo señalado, sin lo quebrantar, porque si hiziere lo contrario, y fuere convencido, incurre en pena de estar doblado tiempo desterrado de lo que le falta. Si fuese el destierro por diez años, y lo quebrantare, se haze perpetuo, y si fuere perpetuo y lo quebrantare incurre en pena de muerte" 49 .

También se produce en este delito la posibilidad de establecer como pena el embargo económico, cuando las alcahuetas tienen bienes, al iniciarse la causa contra ellas. Por lo común, las mujeres que ejercen este oficio no tienen medios materiales o no los tienen en cuantía suficiente. Son pocos los inventarios que acompañan a sus detenciones, al igual que ocurre con los pleitos que se siguen por prostitución ${ }^{50}$. Son sin embargo condenados a costas procesales o a restitución de cantidades a personas concretas.

49 Suma de las Leyes Penales [...].Caso LVI. De Los que quebrantan el destierro que por sentencia fue dado en pena, pp. 70.

50 Sirvan como ejemplo los objetos que se tomaron de casa de la viuda, reincidente, Teresa Guezmes fueron: "Un colchón viejo de terjiz, Un jergón con su paja de estopa viejo, Dos almoadas viejas, Una armadura de cama de madera de pino, Una camilla vieja de lo mismo, Dos silletas de paja buenas, Un cofrezillo pequeño viejo forrado de una vadana negra y dentro de el una mantilla de verano usada, Un abanico negro, Un guardapies de lienzo pintado nuevo, Una casaca de muger de griseta de lana nueva, Un capotillo de tafetán negro mui viejo, Un peto bordado viexo, Un azafatillo de mimbres, Un rosario de Gerusalen, Un espejito, Un par de zapatos de muger negros nuevos, Una efigie de un santo christo a la cabezera de la cama de hueso pequeño, una plancha, un par de tijeras, Un pedazo de calzeta con sus abujas (hace punto, en sus ratos libres), Una zesta de mimbre blanca, Una votella de vidrio, Tres escudillas, Tres jícaras, Dos platos, Una jarra, Un cuenco todo de Talabera ordinaria, Un baso, Una copa de vidrio grandes, Un fuelle viejo, Una copa de varro, Otros diferentes trebajos de cozina, como pucheros y cazuelas viejas, estos por su poca consideración no se anotan". En otro proceso, 775 reales fue todo lo que se le incautó a Manuela Ortiz, alias la Legaña o la galana, viuda vecina de Burgos en 1758 , pero se la había condenado a las costas del proceso y además se intenta que ella misma costee el desplazamiento de Burgos a la cárcel de Valladolid, en la que se la condena por seis años. Valladolid, ARCV., Causas Secretas, 12.3, 1767; Pleitos criminales 1232-5, 1758. 
Por último, en esta tipología delictiva, al igual que en la derivada del ejercicio de la prostitución, tiene un especial protagonismo el apercibimiento $^{51}$. No el apercibimiento procesal sino el penal o punitivo contenido en la sentencia, para evitar la repetición de iguales o similares actos criminales en el futuro ${ }^{52}$. Apercibimientos que son considerados más como remedios que cómo verdaderas penas, o como remedio de éstas, como señala Antonio de la Peña ${ }^{53}$.

Apercibimientos de los que eran partidarios tanto Castillo de Bobadilla como Cerdán de Tallada, por ser una pena arbitraria, muy leve, por debajo de la cual solo está la prevención. Pero si lo vemos como una simple corrección o un medio para purgar sospechas o culpas leves, nos indica el sentido que tienen estos delitos en esta sociedad. De hecho los apercibimientos se encuentran en sentencias por pequeños hurtos, resistencia a las justicias o los de incontinencia, bien sea prostitución o alcahuetería. La finalidad bien pudo ser no añadir más nota y escándalo a los implicados que la que ya se había producido por los hechos y actitudes de los culpados, que en algunas ocasiones, si eran personas de calidad o eclesiásticos, se veían protegidos al no aparecer sus nombres en los papeles generados a lo largo del proceso (testificales, autos, providencias, etc.).

El apercibimiento que viene impuesto en las sentencias está acompañado de una cláusula de quebrantamiento. En esta, en ocasiones se advierte del castigo que se le dará de no cumplir, señalando una pena exacta, mientras que en otras no se pasa de la mera advertencia ${ }^{54}$.

Pero si en general la ejecución de las sentencias de los tribunales penales tiene difícil seguimiento en el Antiguo Régimen, tal y como

51 Apercibimiento. Excitación o requerimiento que se hace a alguno para que ejecute alguna cosa, o para que evite diligentemente faltas u omisiones que, a ser maliciosas constituirían delito", en Diccionario de la Administración española, Tomo 1. Madrid, 1892, p. 474.

52 Pedro Ortego Gil, "Apercibimientos penales en la práctica criminal de la Real Audiencia de Galicia (siglos XVII y XVIII)”, Cuadernos de Historia del Derecho, no 3, 1996, pp. 11-41.

53 "Tratado muy provechoso, útil y necesario de los jueces y orden de los juicios y penas criminales", publicado por M. López-Rey Arrojo, Un práctico castellano del siglo XV. Antonio de la Peña, Madrid, 1935. p. 65.

${ }^{54}$ No obstante, tiene un carácter similar a otras sentencias desde el momento en que cabe recurrir a instancias superiores la pena de apercibimiento, con la diferencia con respecto a otras penas de que no tiene límites temporales. 
se ha señalado para el caso de los destierros, mucho más difícil era controlar por parte de la justicia las sentencias de apercibimiento. En el caso de un tabernero de malas costumbres, llamado Gerónimo Castro, que tenía abierta sobre la tasca una casa de lenocinio, recibió un apercibimiento del alcalde de barrio de Valladolid para que cesase en una actividad escandalosa y en mantener abierta su cantina más allá de las 10, hora en que según el bando municipal debía estar cerrada. Sin embargo, hasta después de las 2 de la madrugada seguía dando vinos, licores, y cama para aquellos hombres que querían estar con alguna de las tres mozas que le servían. No obstante, la sentencia definitiva no incluía apercibimiento, ni otra sanción más que volver en el corto plazo de ocho días a su casa, en la que tiempo atrás había dejado en total abandono y descuido de alimentos a su legítima mujer, a pesar de que después había vivido amancebado con otras, con las que también tenía hijos ${ }^{55}$. Sus delitos por alcahuetería y lenocinio no parecen tenerse en cuenta por el juez, que antepone las necesidades de su esposa a otras cuestiones.

En la sentencia dictada contra un grupo de mujeres de mala vida, que residian todas en una misma casa abandonada (sin arrendar ni pagar renta alguna) fue un apercibimiento, de que si en lo sucesivo diesen margen a algunos desórdenes, como aquellos por los que han sido procesadas, serían tratadas con mayor rigor ${ }^{56}$. Pero, el apercibimiento no tenía por qué ser pena única, y por lo general no lo fue 57 . De hecho, en el pleito anterior se les condenaba a las mujeres a las costas y a salir de Valladolid, es decir, a destierro.

La cárcel galera de mujeres era otra posibilidad, pero no en la primera sentencia. Se apercibía de pena de cárcel en caso de reincidencia, aunque como primera opción se evitaban los encarcelamientos prefiriendo desplazar a las mujeres fueran putas o alcahuetas de sus centros

55 Valladolid, ARCV., Pleitos criminales, 1452-3, 1818.

56 Valladolid, ARCV, Pleitos criminales, 1300,11 1807

57 Pedro Ortego Gil considera que el apercibimiento fue ganando en importancia cuantitativa en las sentencias, en la misma proporción que se producía un descenso en las penas de destierro entre el siglo XVII y el XVIII. "Apercibimientos penales [...], Op. Cit., p. 23. 
de acción, sin tener en cuenta las situaciones que para ellas generaban. Evitaban el mal alejando el peligro.

\section{Penas y sentencias en la literatura no jurídica.}

La aplicación de estas sentencias se vislumbra en la literatura del Siglo de Oro, que no oculta el tratamiento que a las denominadas celestinas suele dar la justicia. Emerenciana, una alcahueta literaria, situada en Alcalá de los Estudios, en la obra titulada El escarmiento del viejo verde, de Salas Barbadiño, es uno de los personajes de este oficio al que se presenta a través de sus habilidades pero antes por las consecuencias que tuvo que sufrir por ejercer este oficio:

"Mujer acreditada con los trabajos de prisiones largas y destierros no cortos, y aun tal vez si había paseado, sacando sus espaldas en público [azotes] y dando que mirar a los doctores y bachilleres de la universidad, en que, gracias a Dios, que sabe acudir en las necesidades, mostró tan buen ánimo y corazón que muchas de su arte la envidiaban y daban mil alabanzas al cielo, que la hizo mujer para tanto".

Igualmente, si leemos el Diario de Ventura Pérez, que recoge los asuntos más llamativos de la vida de Valladolid para el autor durante buena parte del siglo XVIII, y por tanto no es una fuente procesal, pero atiende con puntualidad a reflejar todas las ejecuciones públicas, observamos como con una cierta periodicidad - al menos una por década - se aplica la sentencia a alguna alcahueta que ejercía en Valladolid en esos años, con la publicidad que se daba a todas estas ejecuciones para que fueran ejemplificadoras.

"En 15 de diciembre de 1712 pusieron a la vergüenza en un tablado a unas mujeres y luego las desterraron".

“Año de 1733 día 16 de Junio, emplumaron en medio de la plaza a una mujer por alcahueta, la cara al consistorio; la emplumó el verdugo y la tuvo allí un cuarto de hora con su coraza, y la llevaron por las calles 
públicas de la misma manera; vivía frente del León de la Catedral en una casa donde pocas veces ha faltado fruta de este género”.

"Año de 1735, día 28 de Febrero, emplumaron a Isabel Uso, que vivía a la Pasion, por alcahueta, y la condenaron a seis años de galera: la trajeron sin orden por las calles; después que la emplumaron la pusieron una coraza y la llevaron por la calle de Teresa Gil, calle de Longaniza, Galera y otras calles, y por la tarde la trajeron a la galera, rapada y a la vergüenza”.

“Año de 1749, día 10 de Junio, emplumaron a una mujer, vecina de ella, llamada la Palurda, por alcahueta. La pasearon las calles con plumas y todo; la llevaron a la galera por ocho años a la voluntad de la sala".

"Año de 1754, día 31 de Agosto, emplumaron a una mujer por alcahueta; era de oficio colchonera; hicieron con ella lo mismo que con las demás; era de bastante tomo".

"En 5 de septiembre de 1767 emplumaron a una mujer por alcahueta y haber perdido a diferentes mozas, en la plaza pública, como es costumbre; no la pusieron coraza; desde allí la llevaron a la galera. Salió toda rapada; vivía en la calle de San Martín, a la entrada como vamos a la plazuela vieja a la mano derecha; fueron muy criminosos sus actos".

"En 23 de septiembre de 1770 pusieron en medio de la plaza, a la vergüenza, a tres mujeres, por meretrices; las tuvieron allí más de dos horas y luego las echaron por las puertas de la ciudad desterradas; las tuvieron vestidas solo a cuerpo, rapadas cabeza y cejas".

"En 15 de noviembre de 1780 emplumaron y llevaron a la galera a una alcahueta llamada la Roja pastora".

"En 21 de julio de 1781 emplumaron a un hombre llamado Toribio por alcahuete, frente del consistorio, y le emplumaron en la misma forma que a otras mujeres, solo con la diferencia que a las mujeres las echan plumas de palomino y a este le emplumaron con plumas de ganso, blancas, y de esta forma le volvieron a la cárcel por todas las calles acostumbradas que llevan a los azotados con plumas y bien acompañado, sin azotes" 58 .

58 Diario de Ventura Pérez, fácsimil, Ed. Grupo Pinciano, Valladolid, 1885, p. 120, 130, 272-272, 298, 412, 441, 458, 511, 514. 
$\mathrm{Y}$ atendiendo a las propias sentencias, como la que a mediados del siglo XVIII, se le daba a "la Galana" tras su juicio por alcahueta, se repiten las mismas penas

"La debo condenar y condeno a berguenza publica acompañada con miel, plumas, y coraza, y en seis años de reclusión en la galera y real carcel de miseriordia de la ciudad de Valladolid" 59.

En definitiva, las penas que por sentencia judicial se suelen imponer a las alcahuetas son - como hemos visto - las llamadas penas infamantes. No deja de ser curioso, que se les imponga perder la fama a quien por venir de la profesión que viene se supone que ya la había perdido. Pero, por ejemplo, en el proceso anterior, el discurso del procurador de la condenada era muy contrario a esta idea y por tanto a una pena infamante, pues describía a la penada con adornos muy diferentes:

"porque la dicha... es buena cristiana, ttemerosa de Dios y de su conciencia, enemiga de lo ajeno, ... a la voluntad de su dueño, honesta modesta y recogida de ttal modo que ttanto en el esttado de Biuda en que se halla como en el de casada y de soltera xamas ha dado la mas leve notta ni escandalo pues ha vivido horradamente ni ha sido causa de que muger alguna de ningun estado haia vivido mal".

En cualquier caso, es posible deducir que en el Setecientos los tribunales seguían manteniendo la vergüenza pública. Pero no solo estas penas, pues por otra parte, se opta indiscriminadamente por la cárcel y por el destierro, lo que no se puede interpretar, como hiciera Berni Catalá, como una mitigación de las penas.

Para las mujeres los elementos infamantes fueron numerosos y, además de los azotes, se ponían en escena otros elementos, los que destaca el

59 Además de que se la embargase y con ello se paguase a Manuel Sánchez lo que le debía de unas ropas. Esto es sentencia en Burgos y se remite a Chancillería. Valladolid, ARCV., Pleitos criminales 1232-5, 1758. 
emplumamiento, el paseo, rapar cabeza, y la coroza. Esta pieza, que se les colocaba para el paseo público infamante, se elaboraba para cada una de las condenadas, y tenían que pagar al verdugo que se la proporcionaba:

"Açotaron en Salamanca a una vieja por alcahueta y hechicera. $\mathrm{Y}$ quando la descendieron del asno, dixole al verdugo, que le pagasse los derechos que le debía y entre las cossas contole lo que avia costado la coroça. Dandole cuenta lo que costó el papel y las colores, y la hechura. Pagole, diciendo, dádmela acá hijo, pues cuesta tanto, que no se cuando la avré menester" 60 .

Para algunos autores, no juristas, como Francisco de Monzón, ninguna de estas penas parecía adecuada para este tipo de delincuentes:

“...que como viesen una vieja sin hazienda ninguna vivir y mantenerse bien, era necesidad que se avia de descubrir el arte que tenía, y en siendo hallada una de estas maestras de alcahueterías, devría ser castigada, no solo con pena de infamia de encoroçarla como ahora hacen, porque no lo sienten como afrenta, antes lo huelgan por ser desde allí adelante más conoscidas, para que sepan los vanos hombres aprovecharse de su oficio. Menos les es abastante pena açotarlas y desterrarlas, porque el dolor es liviano, y con el destierro no se estorva el uso de sus malas artes, que adonde quiera que fueren ay mujeres con quien puedan tener sus malos tratos y usar de sus malas mañas. La pena que devría de dar a un juyzio destas tales era herrarlas en la cara, en parte a donde no se pudiesen encubrir las señales por las quales fuese[n] conocidas de todos generalmente y tenidas por sospechosas personas, para que no las consintiesen entrar adonde oviese castas y honestas mujeres a quien pudiesen perjudicar, y avíase de executar esta pena con tanto rigor que por ninguna causa se le avia de perdonar a la que la meresciese, por serle devida justamente. Que si hierran a los que se casan dos vezes ¿Por qué

${ }^{60}$ Floresta española: de apotegmas, o sentencias ...de algunos españoles, En Bruselas, casa de Huberto Antonio Velpio, 1655. capítulo VI. De Iusticiados. XII. 
no herraran a la que haze descasarse muchos hombres y casarse otros a hurtos y esta causa de hazerse muchos adulterios? Y si se sopiese que el juez avía perdonado a alguna por ruegos de algunas personas ... deviera ser castigado reziamente, como a persona que pervirtió la justicia por corruption de personas, y que por su negligencia son corrompidas las buenas costumbres y hechos muchos adulterios y deshonestidades en la cibdad que les está encomendadad para que rigan y la goviernen"61.

Los maridos consentidores generalmente sufrían también una pena infamante, pero según Cobarrubias, que coincide con el autor anterior, no la considera la más apropiada y por la misma razón:

"Para los que han perdido la vergüença, esta pena y la sobredicha no es pena, sino publicidad de su ruin trato, para que sean más conocidos y freqüentados; pero si tras esto los embiassen a galeras, no se iría todo en risa" 62 .

Así pues, tras el análisis del delito de alcahuetería o lenocinio en los manuales de práctica jurídica y en los pleitos criminales y causas secretas seguidas por su causa en el Tribunal de la Chancillería, originados fundamentalmente por autos de oficio, podemos deducir que: en los procesos se observa una intervención clara sobre el que está detrás de los actos deshonestos y concierta voluntades, y no sobre los implicados en tales actos. Se le acusa de inmoralidad, pero no se incide en el aspecto económico y en el negocio que gestiona, no actuando para que resarciera a las mujeres implicadas de ninguna manera. Las sentencias que tienen que afrontar los rufianes y alcahuetas son fundamentalmente apercibimientos, penas infamantes, corporales, destierro, y cárcel, y las mujeres que han trabajado para ellos no serán juzgadas en el mismo proceso.

61 Francisco de Monzón, Libro primero del espejo de la princesa cristiana, Ley V, p. $240 r^{\circ}$ (Archivo Nacional Torre do Pombo).

62 José Julio GARCÍA ARRANZ, "El castigo del "cornudo paciente»: un detalle iconográfico en la visita de Sevilla de Joris Hoefnagel (1593), Norba-Arte, vol. XXVIII-XXIX (2008-2009), pp. 69-79 
Série Investigação

Imprensa da Universidade de Coimbra

Coimbra University Press

2015 